\title{
Performance effects and economic viability of high-hydrated ethanol fumigation and diesel direct injection in a small compression ignition engine
}

\author{
Josimar S. Rosa ${ }^{1}$, Giulio Lorenzini² ${ }^{*}$, Carlos R. Altafini ${ }^{3}$, Paulo R. Wander ${ }^{4}$, Giovani D. Telli ${ }^{1}$, Luiz A.O. Rocha ${ }^{4}$ \\ ${ }^{1}$ Mechanical Engineering Department, Federal University of Rio Grande do Sul, Brazil \\ ${ }^{2}$ Università degli Studi di Parma, Dipartimento di Ingegneria e Architettura, Parco Area delle Scienze 181/A, 43124 Parma, \\ Italy \\ ${ }^{3}$ Mechanical Engineering Graduate Program, University of Caxias do Sul, Brazil \\ ${ }^{4}$ Mechanical Engineering Graduate Program, University of Vale do Rio dos Sinos, Brazil
}

Corresponding Author Email: giulio.lorenzini@unipr.it

https://doi.org/10.18280/mmep.060101

Received: 15 December 2018

Accepted: 18 February 2019

\section{Keywords:}

internal combustion engine, fumigation, economic viability, ethanol, diesel oil

\begin{abstract}
This study investigates the operation of a diesel engine (compression ignition) coupled to an alternator, using mixtures of diesel oil and hydrous ethanol as fuel, with high water content. The mixtures of ethanol and water were injected at the intake manifold (fumigation), while the diesel oil was injected directly in the combustion chamber. The mixtures of ethanol and water were prepared with 90,80 and $70 \%$ of ethanol, at volumetric fraction. The analyzed parameters were energetic and exergetic efficiency, specific fuel consumption, exhaust gas opacity and exhaust gas temperature. The results have shown that the increase of water in hydrous ethanol causes reduction of efficiencies (energetic and exergetic) and increase the specific fuel consumption, however, the gas opacity and the exhaust gas temperature are reduced. Despite the reduction of efficiencies, the use of ethanol with high water fraction is viable because there is potential for fossil fuel substitution by a renewable source. Economically, it was verified that for each condition tested there is a maximum cost of ethanol for viability, and only in 4 out of 27 Brazilian states the use of fumigation of ethanol/water blends technique would be viable, but with the lowest water concentration.
\end{abstract}

\section{INTRODUCTION}

Nowadays, the researches aiming the investigation of the substitution of fossil fuels by renewable fuels have been increasing all around the world. Environmental organizations and researchers have reported the impacts that continuous use of fossil fuels cause to the planet [1-2], specially the diesel oil, because it is a fossil fuel. It is necessary to evaluate alternatives, mainly in internal combustion engines, that are the most common equipment that uses this kind of fuel. The oil crisis reaches a critical level, and in recent years there has been a growing concern about fuel consumption [3].

Alternatively, in the past few years, many studies sought to analyze the use of hydrous ethanol at compression ignition engines, however without using high water volumetric fraction. Munsin et al. [3] mention that the ethanol may be used as fuel in a compression ignition engines, although the greater application is in spark ignition engines, and it can present high efficiencies.

Imran et al. [4] describe, on a review article about the ethanol fumigation technique, that there are many possible methods for a combination of ethanol and diesel in internal combustion engines, however the most common are:

- blends of ethanol and diesel oil, that is, ethanol direct addition to a diesel oil, and direct injection of this blend in the combustion chamber;

- double injection, with two different systems of direct injection in the combustion chamber;

- fumigation, that is, ethanol injection in intake manifold.
The authors stand out that the most investigated technique is fumigation. Fumigation is a term used to describe the methods that apply port fuel injection system, allowing that the engine intakes a load of air and fuel during the intake stroke, as the spark ignition.

Morsy [5] analyzed a compression ignition engine operating with fumigation on port fuel injection of ethanol and water blends, and the diesel direct injection. The blends of ethanol and water were prepared with ethanol volumetric fraction of $25,50,75$ and $100 \%$. The load of the generator set was $85 \%$. The results have shown lower specific fuel consumption while using the diesel oil fuel in comparison to the use of ethanol and water blends. While the ethanol volumetric fraction is reduced, the specific fuel consumption increases. The highest value was obtained when using ethanol without the addition of water. The thermal and exergetic efficiency presented significantly variation for the different test conditions.

Oliveira et al. [6] analyzed the performance and emissions of a generation set. The engine is a four-cylinders and the compression rate is 17, operating with direct injection of diesel oil and ethanol fumigation, without the addition of water to ethanol. The ethanol volumetric fraction (in relation by diesel oil) was between 5 to $30 \%$. The load applied was approximately $70 \%$ of total allowable load. The direct injection diesel has not been modified. The conversion efficiency using ethanol fumigation increased in $13 \%$ compared to the use of diesel oil only.

Padala et al. [7], using a monocylinder engine compression ignition, evaluated the effect of position of ethanol injector at 
the performance, when operating in dual fuel mode (diesel/ethanol). They verified that the position of injector also presents significantly influence on exhaust gases emissions. The efficiency increases up to $20 \%$ of substitution of diesel from ethanol, and above this percentage the efficiency shows a decrease.

Jamuwa et al. [8, 24] investigated the performance, emissions and combustion parameters in a stationary engine of compression ignition using ethanol fumigation. The engine is monocylinder, stroke is $3.7 \mathrm{~kW}$, and compression ratio is 16.5 . The engine was coupled an alternator and the angular velocity was $1500 \mathrm{rpm}$, with variable load. A different ethanol energy fraction was used between 0.1 on 0.7 of the total energy used by the engine. The results have shown that:

- the conversion efficiency was between 25 and 30\%, and the highest values for the energy fraction were around 0.4 ;

- the exergetic efficiency showed approximated values for all energy fraction, as the exhaust gas temperature.

Ferreira et al. [9] evaluated diesel engine air refrigeration with compression ratio equal to 20 and power of $7.6 \mathrm{~kW}$, very similar to the one used in this research, operating with diesel or biodiesel, and ethanol fumigation technique. The diesel substitution per ethanol, in volumetric fraction, was 5, 10 and $15 \%$. The specific consumption of diesel was reduced as function of higher ethanol volume fraction, however the total energy consumption increased. The energetic analysis showed reduction of efficiency due to the ethanol addition. The study also showed that the substitution of $15 \%$ of diesel oil by ethanol is the best condition, energetically.

Zhang et al. [10] studied the operation of a compression ignition engine using fumigation of methanol or ethanol. The engine was coupled to an electrical dynamometer and several loads were applied for the same angular velocity. For $70 \%$ at load and using between 10 to $20 \%$ of ethanol, at mass base, the results showed:

- thermal efficiency for $10 \%$ of ethanol equal to $36.8 \%$, and for $20 \%$ of ethanol equal to $37.4 \%$;

- reduced particulate in smoke as function of increase of ethanol.

Chauhan et al. [11] conducted an experimental study about ethanol fumigation in a small capacity compression ignition engine, coupled to an alternator. The compression ratio is 17.5 and de power electric is $7.5 \mathrm{~kW}$. For the load range similar to the used in this research, it was verified:

- the exhaust gas temperatures reduced due to the ethanol percentage;

- the exhaust gas opacity was also reduced.

In research fulfilled by Britto and Martins [12], a compression ignition engine was evaluated at different compression ratios and loads. The best performance was at compression ratio equal to 17 and $65 \%$ substitution of diesel oil (in energy fraction), being the efficiency equal to $49 \%$ in this condition.

López et al. [13] tested a four-cylinder engine with $59 \mathrm{~kW}$, coupled to a magnetic break, and reported an increase of specific fuel consumption and thermal efficiency reduction when using $10 \%$ of ethanol as fuel. Nour et al. [14] reported the same behavior when using ethanol and water blends, being that the increase of parcel of water contributes for the increase of specific fuel consumption and reduce the thermal efficiency. The particulate concentration drops to 0.2 water fraction and increases above this value.

In other study, Nour et al. [15] used the fumigation technique without water addition combined with exhausting gas recirculation technique, obtaining an increase of specific fuel consumption and a reduction of thermal efficiency as function of ethanol fraction increase.

Zehra et al. [16] used a turbocharged engine, obtained reduction of specific fuel consumption with the increase of ethanol parcel, and the authors consider that the turbocharge may be the reason for the reduction.

The analysis of literature shows that there are variations in results obtained by several authors when using mixtures of diesel oil and hydrous ethanol as fuel, with high water content. While some authors report an increase, others report a decrease of conversion efficiency. This behavior was also verified for specific fuel consumption. The exhaust gas opacity decreased in all studies that analyzed this parameter. A ratio inversely proportional between the conversion efficiency and specific fuel consumption was verified in all studies.

The proposal of the present study was to investigate the use of ethanol with high water fraction (10,20 and 30\% by volume) as fuel in a small generator set, which used a compression ignition diesel engine as primary machine. The applied technique was fumigation, and the engine started operating on a dual fuel mode. The necessary instruments and measurements were performed to evaluate the performance and economic viability. Thus, this research aims to contribute to the expansion of existing data that justify the use of ethanol with high percentage of water in compression ignition engines by fumigation method, and to evaluate the necessary ethanol cost conditions for economic viability, since in Brazil the ethanol cost presents significant variation from region to region.

\section{METHODOLOGY}

\subsection{Equipments and instruments}

The tests using several fuel proportions (diesel oil and ethanol water blends) were conducted in a generator set, originally designed for an operation with diesel oil. The specifications of diesel engine and alternator are presented in Table 1.

Table 1. Characteristics of engine and alternator

\begin{tabular}{cc}
\hline Engine manufacturer/model & Agrale/M93ID \\
Displacement & $668 \mathrm{~cm}^{3}$ \\
Compression ratio & $20: 1$ \\
Number of cylinders & 1 \\
Refrigeration system & Air \\
Alternator manufacturer & Kolbach \\
Power & $10 \mathrm{kVA}$ \\
Voltage & $220 \mathrm{~V}$ \\
\hline
\end{tabular}

Considering the various possibilities of ethanol usage in diesel engine (compression ignition) presented in the literature [4], fumigation was chosen mainly because it requires few changes in the physical structure of engine, and should only be added external components for injection of ethanol and water blends in the intake manifold. Thus, there was no need for alteration in internal components. Figure 1 shows the diagram relating equipments and instruments.

The featured items on the left were installed for fumigation ethanol and water blends. The electric energy produced was dissipated in a set of electrical resistances. For instrumentation, the characteristics were presented on Table 2. 


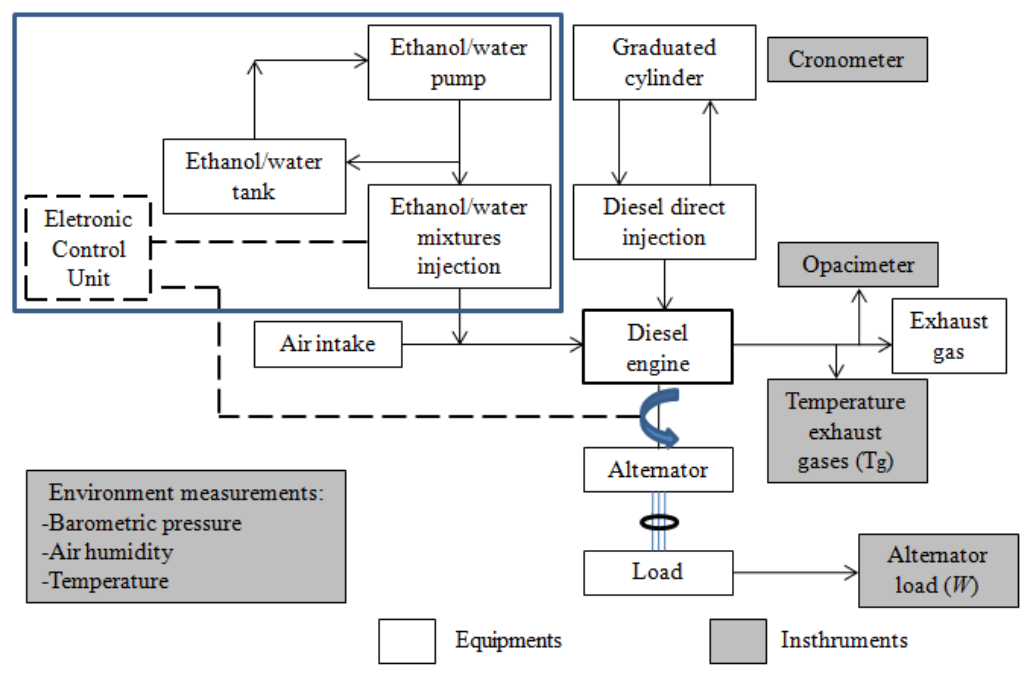

Figure 1. Schematic of the experimental setup

Table 2. Instrumentation and uncertainties

\begin{tabular}{cc}
\hline Energy analyser & $0,5 \%$ \\
Graduate cylinder & $\pm 0,5 \mathrm{ml}$ \\
Opacimeter & $\pm 2 \%$ \\
Thermometer & Sensor: $(\mid \pm 0,3 \%)+\left( \pm 1{ }^{\circ} \mathrm{C}\right)$ \\
& Measuring device: $\pm 2,2 \%$ or $\pm 0,75 \%$ \\
\hline
\end{tabular}

The consumption of ethanol and water blends analysis and time injection management were carried out by a programmable electronic central unit, which allows programming the time that the injector nozzle remains open. Previously, a test was performed to determine a curve of mass flow rate as function of the opening time of the injector nozzle.

\subsection{Characteristics of fuels}

Samples of the fuels used in this experiment were analyzed in laboratory to determine the elemental composition and higher heating value (HHV). The results of characterization are shown in Table 3.

The lower heating value (LHV) was calculated through Eq. (1) [17].

$$
\mathrm{LHV}=\mathrm{HHV}-2440\left(9 \mathrm{y}_{\mathrm{h}}+\mathrm{u}\right)
$$

where $\mathrm{y}_{\mathrm{h}} i s$ the hydrogen mass fraction and $u$ is humidity mass fraction on dry basis. For efficiency calculation, the LHV was used.

Table 3. Characteristics of fuels (composition ${ }^{\mathrm{A}}, \mathrm{HHV}^{\mathrm{A}}$ and $\left.\operatorname{cost}^{\mathrm{B}}\right)$

\begin{tabular}{|c|c|c|}
\hline Parameter & Ethanol & Diesel oil \\
\hline Carbon (\%) & 48.63 & 86.08 \\
\hline Hydrogen $(\%)$ & 13.14 & 12.44 \\
\hline Nitrogen $(\%)$ & 0.03 & 0.04 \\
\hline Sulfur $(\%)$ & - & 0.04 \\
\hline Oxygen $(\%)$ & 38.20 & 1.4 \\
\hline HHV (kJ/kg) & 26920 & 45385 \\
\hline Average cost ${ }^{B}$ & 2.93 & 3.42 \\
\hline Minimum cost ${ }^{B}$ & 2.17 & 2.89 \\
\hline
\end{tabular}

${ }^{\mathrm{A}}$ Composition and $H H V$ measured in laboratory.

${ }^{\mathrm{B}} \mathrm{R}$ \$: Reais, Brazil (ANP, 2018 [27], referring to June).

\subsection{Experimental procedure}

The ethanol water blends were prepared a few moments before the execution of the tests, using a graduated Becker for volumetric measurement. The prepared blends were: $10 \%$ water and $90 \%$ ethanol; $20 \%$ water and $80 \%$ ethanol; $30 \%$ water and $70 \%$ ethanol.

The starting and heating of the engine was performed with diesel oil, operating initially for 15 minutes without load. Then the load was applied through the activation of the circuit breaker. From the load application, the angular velocity was adjusted in $2560 \mathrm{rpm}(60 \mathrm{~Hz})$, then the engine operated in heating for approximately 30 minutes, sufficient time to stabilize the water temperature of resistances tank and exhaust gas temperature. The first test performed used only diesel oil (witness) for further comparisons with the other conditions tested.

After the baseline test, the tests of ethanol+10\% of water, ethanol $+20 \%$ of water and ethanol $+30 \%$ of water, on volumetric basis were carried out respectively. For each of these blends, the time injection and corresponding total flow mass rate are shown in Table 4.

Table 4. Injection time and flow mass rate

\begin{tabular}{cc}
\hline $\begin{array}{c}\text { Injection time } \\
\text { (milliseconds) }\end{array}$ & $\begin{array}{c}\text { Mass flow rate of ethanol/water } \\
\text { blend }(\mathbf{g} / \mathbf{s})\end{array}$ \\
\hline 1.76 & 0.137 \\
2.52 & 0.213 \\
3.76 & 0.336 \\
5.00 & 0.460 \\
7.00 & 0.660 \\
\hline
\end{tabular}

In order to determine the ethanol and water mass fraction in mass flow it was used specific mass of diesel, ethanol and water, measures using a graduate cylinder and a balance. The values obtained were $0.843 \mathrm{~g} / \mathrm{cm}^{3}$ for diesel oil and 0.804 $\mathrm{g} / \mathrm{cm}^{3}$ for ethanol without the addition of water.

\subsection{Uncertainties analysis}

Based on the instruments uncertainty, the uncertain propagated for the efficiency and specific fuel consumption was calculated. The method used was the one proposed by 
Kline e McClintock [18]. Assuming that the R parameter as function of two or more independents variables, $\mathrm{x}_{1}, \mathrm{X}_{2}, \mathrm{X}_{3} \ldots \mathrm{x}_{\mathrm{n}}$ :

$\mathrm{R}=\mathrm{R}\left(\mathrm{x}_{1}, \mathrm{x}_{2}, \mathrm{x}_{3}, \ldots \mathrm{x}_{\mathrm{n}}\right)$

The total uncertainty of R parameteris defined by Eq. (3).

$I_{R}=\sqrt{\left(\frac{\partial R}{\partial x_{1}} I_{1}\right)^{2}+\left(\frac{\partial R}{\partial x_{2}} I_{2}\right)^{2}+\left(\frac{\partial R}{\partial x_{n}} I_{n}\right)^{2}}$

where $I_{1}, I_{2}$ e $I_{n}$ are the uncertainty for independent variables.

\subsection{Equations}

For conversion efficiency, specific fuel consumption and exergetic efficiency when diesel oil mode operation, the Eq. (4), Eq. (5) and Eq. (6) were used.

$\eta_{\mathrm{d}}=\frac{\dot{\mathrm{W}}}{\dot{\mathrm{m}}_{\mathrm{d}} \cdot \mathrm{LHV}_{\mathrm{d}}}$

$\mathrm{SC}_{\mathrm{d}}=\frac{\dot{\mathrm{m}}_{\mathrm{d}}}{\dot{\mathrm{W}}} \cdot 3600$

$\eta_{\varepsilon d}=\frac{\dot{\mathrm{W}}}{\dot{\mathrm{m}}_{\mathrm{d}} \cdot \varepsilon_{\mathrm{d}}}$

For dual fuel operation, the parameters above were calculated using Eq. (7), Eq. (8) and Eq. (9).

$$
\begin{aligned}
& \eta_{\mathrm{df}}=\frac{\dot{\mathrm{W}}}{\dot{\mathrm{m}}_{\mathrm{d}} \cdot \mathrm{LHV}_{\mathrm{d}}+\dot{\mathrm{m}}_{\mathrm{e}} \cdot \mathrm{LHV}_{\mathrm{e}}} \\
& \mathrm{SC}_{\mathrm{df}}=\frac{\dot{\mathrm{m}}_{\mathrm{d}}+\frac{\mathrm{LHV}_{\mathrm{e}}}{\mathrm{LHV}_{\mathrm{d}}} \cdot \dot{\mathrm{m}}_{\mathrm{e}}}{\dot{\mathrm{W}}} \cdot 3600 \\
& \eta_{\varepsilon d f}=\frac{\dot{\mathrm{W}}}{\left(\dot{\mathrm{m}}_{\mathrm{d}} \cdot \varepsilon_{\mathrm{d}}+\dot{\mathrm{m}}_{\mathrm{et}} \cdot \varepsilon_{\mathrm{et}}\right)}
\end{aligned}
$$

In case of Eq. (8), the term $\frac{\mathrm{LHV}_{e}}{\mathrm{LHV}_{d}} \cdot \dot{m}_{e}$ represents the ethanol mass that is equivalent, in terms of energy, in diesel oil mass. Thus, the analysis is realized on the same mass basis.

The exergy of fuels was calculated based in the composition, presented in Table 3, using the Eq. (10) [17].

$$
\varepsilon=\left[1,0401+0,1728 \frac{\mathrm{y}_{\mathrm{h}}}{\mathrm{y}_{\mathrm{c}}}+0,0432 \frac{\mathrm{y}_{\mathrm{o}}}{\mathrm{y}_{\mathrm{c}}}+0,2169 \frac{\mathrm{y}_{\mathrm{s}}}{\mathrm{y}_{\mathrm{c}}}\left(1-2,0628 \frac{\mathrm{y}_{\mathrm{h}}}{\mathrm{y}_{\mathrm{c}}}\right)\right] \cdot \mathrm{LHV}
$$

The replacement of diesel oil by ethanol was calculated as function of mass flow of diesel in baseline test $\left(\dot{\mathrm{m}}_{\mathrm{d}, \mathrm{i}}\right)$ and the mass flow of diesel in current test $\left(\dot{\mathrm{m}}_{\mathrm{d}}\right)$, using Eq. (11).

$\mathrm{S}=\frac{\dot{\mathrm{m}}_{\mathrm{d}, \mathrm{i}}-\dot{\mathrm{m}}_{\mathrm{d}}}{\dot{\mathrm{m}}_{\mathrm{d}, \mathrm{i}}} \cdot 100$

In order to calculate the air excess, the volumetric flow rate of the engine was determined, by Eq. (12), as function of displacement and angular velocity.

$\dot{\mathrm{V}}=\mathrm{V} \frac{\mathrm{N}}{2.60}$

For conversion volumetric flow rate into mass flow, the ambient air specific mass was used, under the conditions that were found in each test. The air specific mass was calculated using the ideal gas state equation, Eq. (13).

$\rho=\frac{\mathrm{P}}{\mathrm{R} \cdot \mathrm{T}}$

\section{RESULTS AND DISCUSSIONS}

The results were obtained using the instruments and equations showed in methodology. The symbology adopted informs the composition of ethanol/water blends at volumetric basis, and the results are presented according to the type of blend. The fuels consumption and substitution are shown in Table 5 .

Table 5. Fuel consumption and substitution

\begin{tabular}{ccccc}
\hline Test & Diesel oil consumption [g/s] & Ethanol consumption [g/s] & Substitution [\%] & Lambda \\
\hline Baseline & 0.606 & 0.000 & 00.00 & 1,77 \\
\hline E90W10_1.76 & 0.500 & 0.120 & 17.49 & 1,86 \\
E90W10_2.52 & 0.451 & 0.187 & 25.59 & 1,90 \\
E90W10_3.76 & 0.374 & 0.295 & 38.36 & 1,92 \\
E90W10_5.00 & 0.310 & 0.404 & 48.82 & 1,91 \\
E90W10_7.00 & 0.252 & 0.579 & 58.46 & 1,75 \\
\hline E80W20_1.76 & 0.534 & 0.104 & 12.03 & 1,81 \\
E80W20_2.52 & 0.487 & 0.162 & 19.70 & 1,84 \\
E80W20_3.76 & 0.419 & 0.256 & 30.85 & 1,87 \\
E80W20_5.00 & 0.356 & 0.351 & 41.23 & 1,89 \\
E80W20_7.00 & 0.281 & 0.503 & 53.74 & 1,82 \\
\hline E70W30_1.76 & 0.546 & 0.089 & 09.91 & 1,81 \\
E70W30_2.52 & 0.504 & 0.138 & 16.97 & 1,84 \\
E70W30_3.76 & 0.443 & 0.219 & 27.02 & 1,87 \\
E70W30_5.00 & 0.394 & 0.300 & 35.11 & 1,87 \\
E70W30_7.00 & 0.325 & 0.430 & 46.48 & 1,83 \\
\hline
\end{tabular}


Greater substitutions correspond to the tests with lower water portions, reaching $58.46 \%$. The electric power applied to the alternator was constant and equal to $5.6 \mathrm{~kW}$.

\subsection{Energy and exergy efficiency}

The value of LHV and exergy of fuels were initially calculated, and the results are presented in Table 6 .

Table 6. LHV and exergy of ethanol and diesel

\begin{tabular}{ccc}
\hline Fuel & LHV (Eq. 1) $-\mathbf{J} / \mathbf{k g}$ & Exergy $($ eq. 10) $-\mathbf{J} / \mathbf{k g}$ \\
\hline Ethanol & 24034.5 & 26939.0 \\
Diesel oil & 42653.2 & 45461.7 \\
\hline
\end{tabular}

The ethanol exergy calculated was $12 \%$ higher than the LHV, while for diesel oil the value was $7 \%$ higher than the LHV. Based on electric power generated, on fuel consumption, on LHV and on exergy, the energy and exergy efficiency were calculated. The results are shown in Figure 2.

In all cases the energy efficiency is greater than the exergy efficiency, which was thermodynamically expected because the energy availability is greater than the LHV.

It is possible to verify that the three curves of efficiencies show similar behaviors, in which there is a tendency for baseline value when reduced the substitution of diesel oil, and gradual increase of efficiency with subsequent fall in the highest substitution. The increase on water content cause reduction on efficiencies, demonstrating that the water contributes for some deficiency in combustion process. This fact has been reported in literature by Morsy [5].
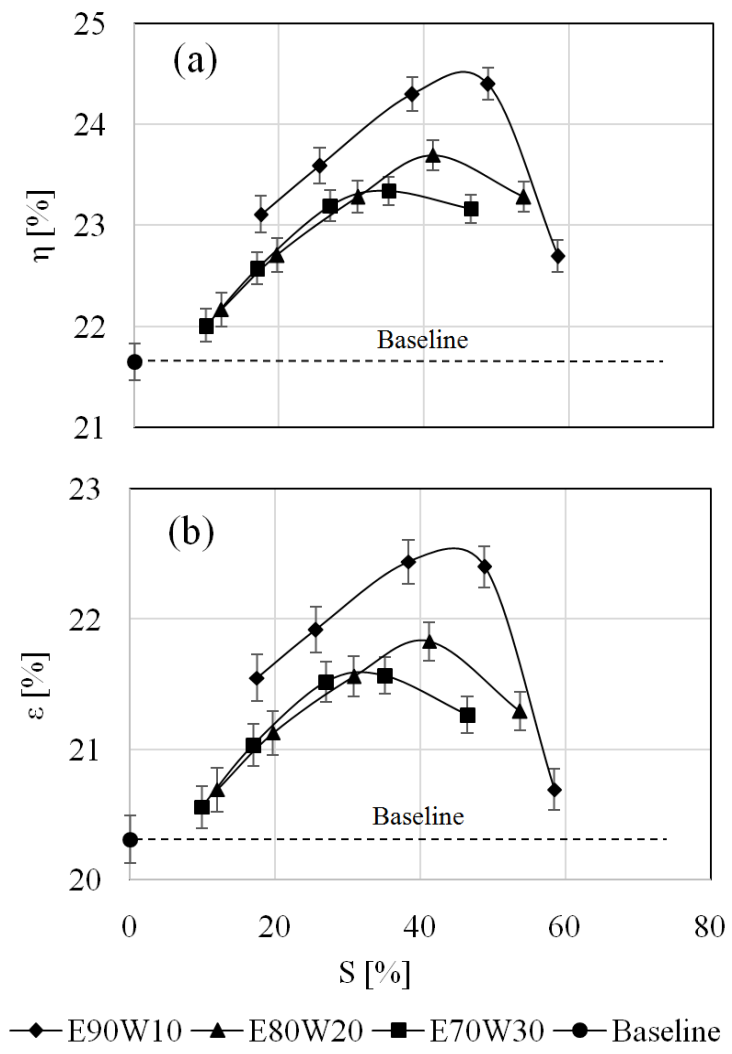

Figure 2. Energy (a) and exergy (b) efficiency

Oliveira et al. [6] report an increase of thermal efficiency while it was increased the substitution of diesel oil per ethanol, mainly at high loads (above 50\%). According to these authors, at high loads, a lot of fuel is burned, increasing the exhaust gas temperature, and this effect, connected to the large mass fuel burned in the premixed phase, are the determinant factors in the reduction or the increase of efficiencies. The tests with blends at $30 \%$ of water showed an increase of exergetic efficiency when compared to the baseline condition. For the energy efficiency, the lowest values obtained, using $30 \%$ of water, were higher than those obtained in the baseline test, only getting range of witness value in minimum substitution, when analyzing the uncertainties.

Tests performed with blends at $20 \%$ of water ensured that the energetic efficiency was greater than the original condition operating only with diesel oil. The biggest difference occurred at $41.2 \%$ of substitution of diesel, when the efficiency was $23.7 \%$, approximately $9.5 \%$ above the efficiency in the baseline test.

In $10 \%$ water blend tests, the energetic and exergetic efficiency showed values above those obtained in the baseline tests. The maximum energetic efficiency obtained was $24.4 \%$, approximately $12.7 \%$ above the baseline value.

The low ethanol cetane number caused more ignition delay, and consequently higher rate of heat release. As a result, there was a reduction of heat lost to the cylinder walls and increase thermal efficiency [5, 8]. Oliveira et al. [6] report in their research $13 \%$ increase in efficiency when use ethanol fumigation on diesel engine. Jamuwa et al. [8] report that the high ethanol flame front velocity resulting in a higher portion of combustion in the premixed phase and reduction of the diffusive flame. According to the authors, the premixed combustion is improved over diffusive flame, contributing to increase the efficiency.

\subsection{Specific fuel consumption}

The results obtained for specific fuel consumption are presented in Figure 3.

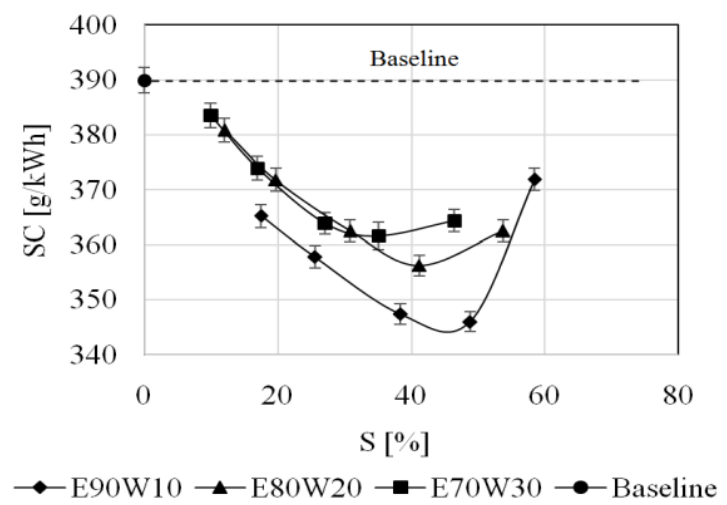

Figure 3. Specific fuel consumption

The total specific fuel consumption (diesel oil and ethanol) was below the obtained in the baseline test, in all percentages of substitution, for the three blends ethanol /water. The best conditions of specific fuel consumption were obtained with $10 \%$ of water in blends, indicating that the water contribute for reduction of engine performance and also the efficiency. The lower value obtained was $345.92 \mathrm{~g} / \mathrm{kWh}$, which is, $11.3 \%$ below the original condition. The worst condition of fuel consumption was obtained for $30 \%$ water mixture, at $10 \%$ substitution, with $1.63 \%$ reduction. However, this value is less than the one obtained with the baseline test. Similar results are 
presented by Chauhan et al. [11].

For low substitution conditions, the blends with 10 and $20 \%$ of water, presented overlapping results, and considering the uncertainties, there is no way to differentiate them. Nour et al. [15] report that an increase of specific consumption as function of increase water fraction is justified by blend heat value reduction, and consequent released heat and power reduction.

\subsection{Exhaust gas opacity}

The exhaust gas opacity was measured during the testes. The results are shown in Figure 4.

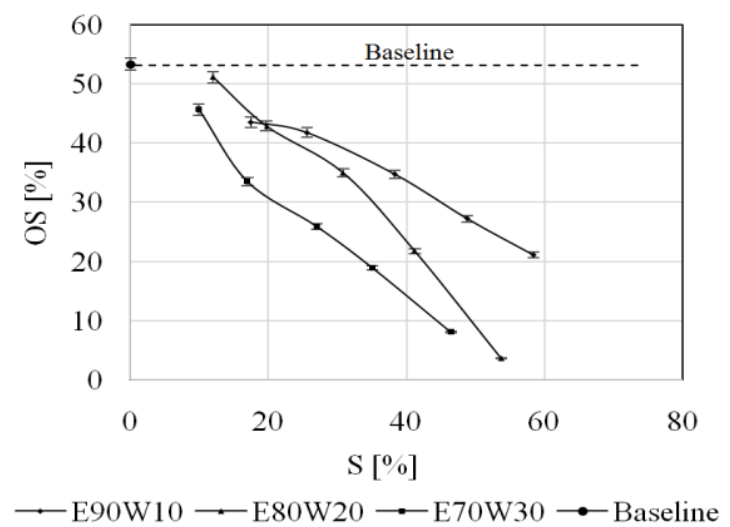

Figure 4. Opacity smoke

For all cases using ethanol/water blends, the value of opacity smoke was below that the one obtained using diesel oil only. With larger portions of water and higher replacement percentages, the opacity was reduced. The opacity is a characteristic emission of diesel oil combustion and with the substitution of diesel by ethanol/water blends it is expected the reduction of smoke opacity, which is reported in literature $[4$, 20-21]. The reduction arising from the increase of water parcel occurs due to the dilution of exhaust gases in water vaporized during the combustion process.

For Nour et al. [14], when there is more ignition delay, just as it does when using ethanol by fumigation in compression ignition and water mass fraction increase, there is more time to homogenize the air fuel mixture, causing reduction in excess fuel regions, and reducing the particulate matter emissions. Besides that, the ethanol addition causes an increase of $\mathrm{OH}$ radicals, promoting the soot oxidation. López et al. [13] report that the ethanol fumigation causes reduction of particulate matter emissions compared to diesel oil conventional operation, probably by the oxygen present in ethanol and by the reduction of sulfur in the total used fuel.

\subsection{Exhaust gas temperature and air excess}

The results of exhaust gas temperature are show in Figure 5. For all tests using ethanol/water blends the exhaust gas temperature were lower than the temperature using only diesel oil (witness tests). There are similar trends for the three types of used blends, dropping the temperature when the substitution increases. Considering the uncertainty of temperature mesuare, it is not possible to conclude how the different water parcels influence in the temperature. The lower temperature recorded was $500{ }^{\circ} \mathrm{C}$ during the test with $10 \%$ of water in ethanol, when the substitution percentage was approximately $48.8 \%$. There are results that confirm this tendency in the literature $[5,21]$.
Oliveira et al. [6] describe that the air entering in the cylinder is cooled when ethanol is admitted in the intake manifold, causing leaning of mixture air/fuel and reduction of air specific volume. The mixture with higher amount of air can cause dilution and reduction of exhaust gas temperature.

Exhaust gas temperatures below those obtained at baseline tests were reported by Morsy [5] for all ethanol/water blends. Goldsworthy [22] reported some factors that can contribute to reduction of temperature: the latent heat vaporization of ethanol can reduce the air temperature at entrance; the water steam reduces the combustion temperature, and the lower flame temperature of ethanol $(2155 \mathrm{~K})$ in comparison to diesel $(2305 \mathrm{~K})$. The highest values obtained for efficiency can also represent a reduction in exhaust gas temperature, because more energy is converted in order to work. The temperature drop of the exhaust gases can be attributed to vaporization of part of the ethanol that occurs only inside the combustion chamber [19].

Some authors relate the exhaust gas temperature to air excess [5-9]. The air excess curves are showed in Figure 6.

Note that, in the same way as in the former results, the values tend to be obtained in the baseline condition. For E90W10 curve, in comparison with the corresponding temperature curve of the exhaust gas, Figure 5, it is verified that the increased air excess results in exhaust gas temperature reduction, and at high substitution, there is a notable increase in exhaust gas temperature, while the air excess decreases significantly.

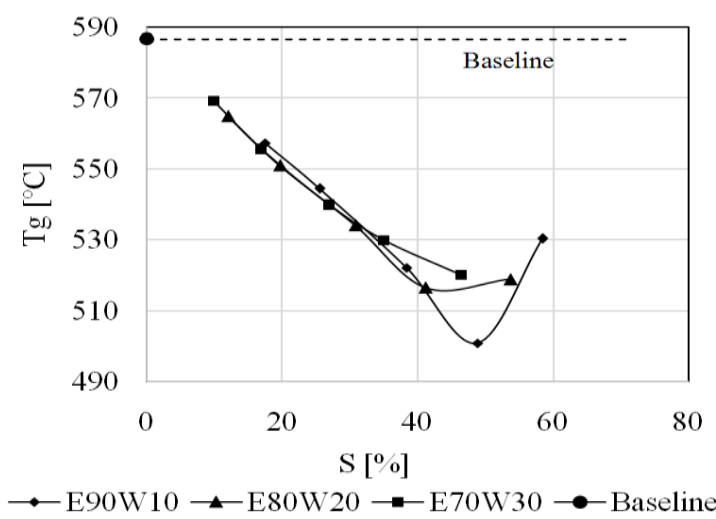

Figure 5. Exhaust gas temperature

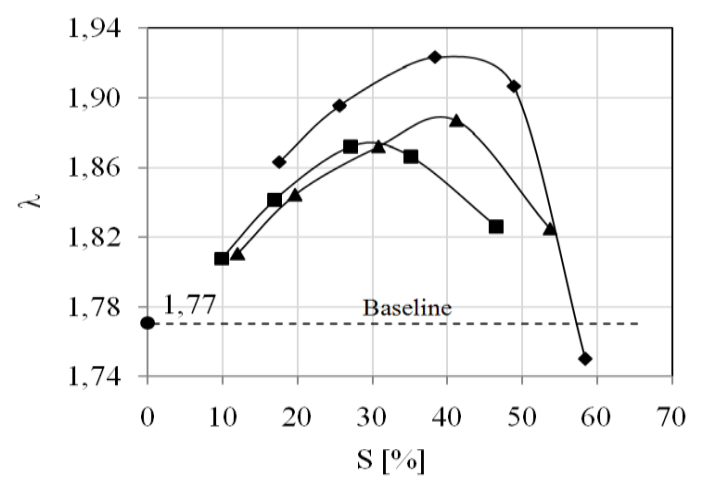

$\multimap$ E90W10 ↔E80W20 -E70W30 •-Baseline

Figure 6. Air excess

For E80W20 curve the relation between air excess and exhaust gas temperature is less pronounced in high substitution, there is less decrease of air excess and lower 
increase of temperature, comparing to E90W10 curve. The values reduction across the curve, related to E90W10 curve, are evident due to the reduction in specific fuel consumption, reported in Figure 3. Analyzing the E70W30 curve, it is verified that the air excess presents similar values to E80W20 curve, at low substitution, and in the two largest substitutions the values are smaller, while there is no increase in exhaust gas temperature. With the increase of water mass fraction in ethanol, the diesel oil consumption increases and the air excess is reduced, because the air fuel ratio for diesel is significantly higher than ethanol.

For each condition presented in Table 5, it was estimated the adiabatic flame temperature, using energy balance, as presented by Turns [25]. Graphically, the results are shown in Figure 7, where the identification with " $\mathrm{V}$ " means constant volume, and the "P" means constant pressure.

There is a reduction in adiabatic flame temperature in all cases when using fumigation of water/ethanol blends in comparison to baseline condition with diesel oil, due to the lower adiabatic flame temperature of ethanol. Only at greater substitution in each curve the decrease tendency is not verified, because in such conditions the specific fuel consumption increases, as shown in Figure 3, mainly as a result of the diesel consumption increase, which has greater adiabatic flame temperature. The E80W20 and E70W30 curves have higher AFT then E90W10 curve, because the increase of water fraction in ethanol/water blends decrease the ethanol consumption and increase the diesel oil consumption, for the same charge and angular velocity. This increase in diesel consumption leads to greater AFT.

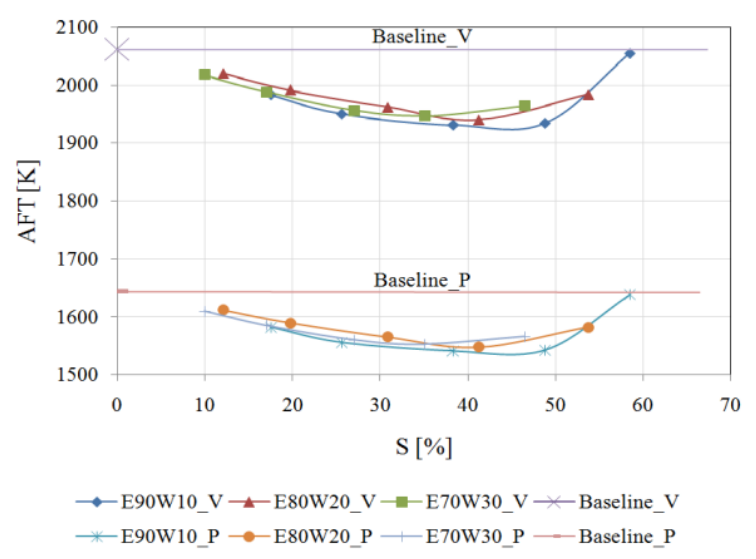

Figure 7. Estimated adiabatic flame temperature

\subsection{Fuel cost}

Based on research conducted by the National Petroleum Agency, the average cost of common diesel oil and ethanol was verified, and the lowest cost of ethanol in June 2018 in Brazil [27], previously presented in Table 3. From this data, two distinct scenarios were analyzed:

a) The cost of electricity produced, considering the average cost of ethanol and the average cost of diesel oil in the country;

b) The cost of electricity produced, considering the lowest cost of ethanol and the average cost of diesel oil in the country.

In Brazil, there is a significant difference in the prices of ethanol from region to region, since the production is not decentralized, increasing distribution costs. There are also different percentages of taxation in each state, which contributes to the different prices found. In both cases, the cost of diesel oil taken into consideration was the national average, which presents greater price stability throughout the national territory. The results are presented in Figure 8.

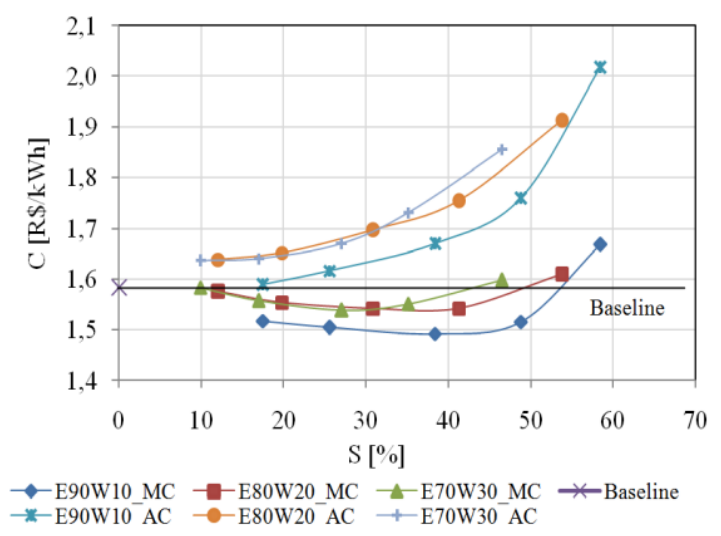

Figure 8. Fuel cost. MC: minimum cost; AC: average cost

Considering the lower cost of ethanol (MC), it is verified that there is economic feasibility for its use in most cases, and only with the highest percentage of substitution of each curve the cost per kWh of electric energy produced becomes greater than the one obtained for the original condition operation with diesel only. The higher cost refers to the higher replacement percentage of the E90W10_MC curve, being 5.29\% higher than the one obtained with diesel oil alone. However, this same curve also presents the minimum value of cost in the third substitution percentage, 5.85 below the original diesel condition. From the economic point of view, this would be the best operating condition among the tests which were carried out, considering the lower price of ethanol in the country.

When considering the average cost of ethanol, in all cases the energy produced cost is higher than the one obtained for the original condition with diesel oil only. The E90W10_AC curve shows the smallest difference, below $0.1 \%$ in the lowest substitution percentage, and also the largest difference, equal to $27.35 \%$, in the highest substitution percentage. This is consistent to the increase in specific consumption as shown in Figure 3. Considering the average price of diesel oil, the maximum price that ethanol (VEC - viable ethanol cost) has to be calculated was calculated so that the cost of generation becomes economically viable in relation to the cost of the original diesel oil generation. The results are shown in Figure 9.

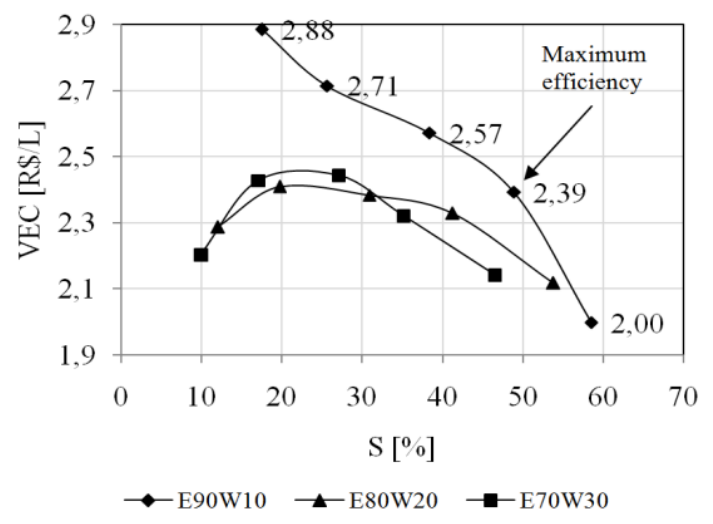

Figure 9. Maximum ethanol cost for economic viability by fumigation

Among all the tested conditions, the highest maximum cost presented was $R \$ 2.88$, while the lowest was equal to $R \$ 1.99$, 
both conditions presented in the E90W10 curve. With the highest substitution percentage, the three curves present an apparent tendency to the same values, which means that there is a reduction of the maximum cost with the reduction of the water fraction, comparing the conditions of grater substitution.

In the largest substitutions of each curve, the maximum cost is below the lowest found by ANP research, showing that in these ranges of operation there is economic unviability for the use of ethanol with a high water fraction. For all other conditions, considering the minimum price of ethanol, the use becomes economically viable.

When considering the highest efficiency condition obtained, previously shown in Figure 2, the maximum cost of ethanol for economic viability was $\mathrm{R} \$ 2.39$, as highlighted in Figure 8, and none of the Brazilian states has an average cost of ethanol lower than this value. The lowers average value is equal to R\$2.60 in the State of São Paulo, which, according to the results of this research, makes the use of ethanol blends with $10 \%$ water (E90W10) in the two lowest percentages of replacement $(17.49 \%$ and $25.59 \%$ ) economically viable. For these percentages, the use is also feasible in the States of Goiás, Paraná and Mato Grosso states. According to the estimate of the ethanol production of 2017/2018 crop published by CONAB [26], these states are among the six largest producers in the country, which is directly related to the lowest cost.

However, if ethanol is produced decentralized, in a small rural property, for example, the final cost of ethanol can be reduced due to the reduction in transport distance. Moreover, the production cost can be reduced when the ethanol is not distilled to the required concentration in regulation [23].

\section{CONCLUSIONS}

The fumigation ethanol/water technique in a compression ignition engine proved to be simple to apply, because it does not need changes in the physical structure of the engine. Then it becomes an alternative for using in vehicles and generators whichuse diesel oil, seeking an alternative for this fossil fuel. However, there is a need to evaluate each engine model distinctly, considering the particularities. The main conclusions obtained in this research were:

(a) The diesel oil substitution causes an increase of energetic efficiency in all cases evaluated;

(b) The increase of water fraction in blends caused reduction of energy and exergy efficiency;

(c) There is a decrease in specific fuel consumption for all cases evaluated, in comparison to the baseline test;

(d) The exhaust gas opacity was reduced with ethanol/water blends fumigation; larger fractions of water caused reduction of opacity smoke;

(e) The exhaust gas temperature is reduced due to the higher substitution of diesel oil;

(f) There is an economic viability of fumigation highhydrous ethanol only in some Brazilian states, especially in those that are the largest ethanol producers.

The present results show that fumigation ethanol/water blends in a compression ignition engine isa viable technique, mainly because it does not cause performance reduction, with reduction of opacity and possibility of economic viability. In addition, it is considered positive to replace a fossil fuel with a renewable one.

\section{REFERENCES}

[1] UNITED States Environmental Protection Association. The Sources and Solutions: Fossil Fuels, from https://www.epa.gov/nutrientpollution/sources-andsolutions-fossil-fuels, accessed on 24 Jul. 2018.

[2] INTERNATIONAL Energy Agency. Energy Technology Perspective 2017: Catalyzing Energy Technology Transformations, from https://webstore.iea.org/energy-technologyperspectives-2017, accessed on 24 Jul. 2018.

[3] Huang TZ, Zhang DJ, Zhai DH, Ma QH, Sheng YY. (2016). An analysis for the body of economy power racing car based on double platform of the XFLOW and FLUENT. Mathematical Modelling of Engineering $\begin{array}{lll}\text { Problems } & 3(2) \text { : } & \text { 75-80. }\end{array}$ https://doi.org/10.18280/mmep.030206

[4] Munsin R, Laoonual Y, Jugjai S, Matsuki M, Kosaka H. (2015). Effect of glycerol ethoxylate as an ignition improver on injection and combustion characteristics of hydrous ethanol under CI engine condition. Energy Conversion Management 98: 282-289. https://doi.org/10.1016/j.enconman.2015.03.116

[5] Imran A, Varman M, Masjuki HH, Kalam MA. (2013). Review on alcohol fumigation on diesel engine: A viable alternative dual fuel technology for satisfactory engine performance and reduction of environment concerning emission. Renewable and Sustainable Energy Reviews 26: 739-751. https://doi.org/10.1016/j.rser.2013.05.070

[6] Morsy MH. (2015). Assessment of a direct injection diesel engine fumigated with ethanol/water mixtures. Energy Conversion and Management 94: 406-414. https://doi.org/10.1016/j.enconman.2015.01.086

[7] de Oliveira A, de Morais AM, Valente OS, Sodré JR. (2017). Combustion, performance and emissions of a diesel power generator with direct injection of B7 and port injection of ethanol. Journal of the Brazilian Society of Mechanical Sciences and Engineering 39: 1087-1096. https://doi.org/10.1007/s40430-016-0667-7

[8] Padala S, Kook S, Hawkes ER. (2014). Effect of ethanol port-fuel-injector position on a dual fuel combustion in a automotive size diesel engine. Energy and Fuels 28: 340348. https://doi.org/10.1021/ef401479s

[9] Jamuwa DK, Sharma D, Soni SL. (2016). Experimental investigation of performance, exhaust emission and combustion parameters of stationary compression ignition engine using ethanol fumigation in dual fuel mode. Energy Conversion and Management 115: 221231. https://doi.org/10.1016/j.enconman.2016.02.055

[10] Ferreira VP, Martins J, Torres EA, Pepe IM, de Souza JR. (2013). Performance and emissions analysis of additional ethanol injection on a diesel engine powered with a blend of diesel-biodiesel. Energy for Sustainable Development 17: 649-657. https://doi.org/10.1016/j.esd.2013.08.005

[11] Zhang ZH, Tsang KS, Cheung CS, Chan TI, Yao CD. (2011). Effect of fumigation methanol and ethanol on the gaseous and particulate emissions on a direct injection diesel engine. Atmosphere Environment 45: 2001-2008. https://doi.org/10.1016/j.atmosenv.2010.12.019

[12] Chauhan BS, Kumar N, Pal SS, Du JY. (2011). Experimental studies on fumigation of ethanol in a small capacity Diesel engine. Energy 36: 1030-1038. https://doi.org/10.1016/j.energy.2010.12.005 
[13] Britto RF, Martins CA. (2015). Emission analysis of a diesel engine operation in diesel-ethanol dual-fuel mode. Fuel 148:

191-201. https://doi.org/10.1016/j.fuel.2015.01.008

[14] López AF, Cadrazco M, Agudelo AF, Corredor LA Vélez JA, Agudelo JR. (2015). Impact of n-butanol and hydrous ethanol fumigation on the performance and pollutant emissions of an automotive diesel engine. Fuel 153: 483-491. https://doi.org/10.1016/j.fuel.2015.03.022

[15] Nour M, Kosaka H, Sato S, Bady M, Abdel-Rahman AK, Uchida K. (2017). Effect of ethanol/water blends addition on diesel fuel combustion in RCM and DI diesel engine. Energy Conversion and Management 149: 228243. https://doi.org/10.1016/j.enconman.2017.07.026

[16] Nour M, Kosaka H, Sato S, Bady M, Abdel-Rahman AK, Uchida K. (2017). Effect of ethanol/water blends addition on diesel fuel combustion in RCM and DI diesel engine. Energy Conversion and Management 164: 33-50. https://doi.org/10.1016/j.enconman.2017.07.026

[17] Zehra S, Orhan D, Mustafa K. (2015). Experimental investigation of improving diesel combustion and engine performance by ethanol fumigation-heat release and flammability analysis. Energy Conversion Management 89: $175-187$. https://doi.org/10.1016/j.enconman.2014.09.053

[18] Vlassov D. (2001). Combustíveis, combustão e câmaras de combustão. Curitiba, PR: UFPR.

[19] Kline SJ, McKlintone FA. (1953). Describing the uncertainties in single sample experiments. Mechanical Engineering 3-8.

[20] Kotas TJ. (1985). The exergy method of thermal plants analysis. University of London.

[21] Geng P, Cao E, Tan Q, Wei L. (2017). Effects of alternative fuels on the combustion characteristics and emission products from diesel engines: A review. Renewable and Sustainable Energy Reviews 71: 523-534. https://doi.org/10.1016/j.rser.2016.12.080

[22] Bae C, Kim J. (2017). Alternative fuels for internal combustion engines. Proceedings of the Combustion Institute 36 :

$3389-3413$ https://doi.org/10.1016/j.proci.2016.09.009

[23] Goldsworthy L. (2013). Fumigation of a heavy-duty common rail marine diesel engine with ethanol-water mixtures. Experimental Thermal and Fluid Science 47: 48-59.

https://doi.org/10.1016/j.expthermflusci.2012.12.018

[24] Mayer FD, Cunha GÁ, Baldo V, Ambros WM, Hoffmann R. (2012). Aspectos da produção de álcool combustível super-hidratado (ACSH) e sua utilização em veículos automotores. XIV Congresso Brasileiro de Energia.

[25] Jamuwa DK, Sharma D, Soni SL. (2017). Experimental investigation of performance exhaust emission and combustion parameters of compression ignition engine with varying ethanol energy fractions. Energy 127: 544557. https://doi.org/10.1016/j.energy.2017.03.121

[26] Turns SR. (2013). Introdução a combustão: conceitos e aplicações. 3. ed. Porto Alegre, RS: AMGH.

[27] COMPANHIA Nacional de Abastecimento - CONAB. Acompanhamento da safra brasileira: cana de açúcar. Brasília: 2017.

[28] AGÊNCIA Nacional de Petróleo, Gás Natural e Biocombustíveis - ANP. Série histórica de preços e de margens de comercialização de combustíveis, from http://www.anp.gov.br/precos-e-defesa-daconcorrencia/precos/levantamento-de-precos/seriehistorica-do-levantamento-de-precos-e-de-margens-decomercializacao-de-combustiveis, accessed on 24 Jul. 2018.

\section{NOMENCLATURE}

$\begin{array}{ll}\text { AFT } & \text { Adiabatic flame temperature } \\ \mathrm{C} & \text { Fuel cost } \\ \mathrm{HHV} & \text { High Heating Value } \\ \text { LHV } & \text { Low Heating Value } \\ \dot{\mathrm{m}} & \text { Mass flow rate } \\ \mathrm{N} & \text { Angular speed } \\ \mathrm{OS} & \text { Opacity smoke } \\ \mathrm{SC} & \text { Specific fuel consumption } \\ \mathrm{S} & \text { Diesel oil substitution } \\ \mathrm{T}_{\mathrm{g}} & \text { Exhaust gas temperature } \\ \tilde{\mathrm{V}} & \text { Volumetric flow rate } \\ \mathrm{V} & \text { Volume } \\ \mathrm{VEC} & \text { Viable ethanol cost } \\ \dot{\mathrm{W}} & \text { Eletric power } \\ y & \text { Mass fraction }\end{array}$

\section{Greek symbols}

$\begin{array}{ll}\varepsilon & \text { Exergy } \\ \lambda & \text { Air excess } \\ \mathrm{H} & \text { Efficiency } \\ \text { Subscripts } & \\ c & \text { Carbon } \\ d & \text { Diesel oil } \\ d f & \text { Dual fuel } \\ d, i & \text { Diesel oil initial } \\ e & \text { Ethanol } \\ h & \text { Hydrogen } \\ o & \text { Oxygen } \\ s & \text { Sulfur } \\ \varepsilon & \text { Exergy }\end{array}$

